\title{
Metformin and lung cancer risk in patients with type 2 diabetes mellitus
}

\author{
Chin-Hsiao Tseng ${ }^{1,2,3}$ \\ ${ }^{1}$ Department of Internal Medicine, National Taiwan University College of Medicine, Taipei, Taiwan \\ ${ }^{2}$ Division of Endocrinology and Metabolism, Department of Internal Medicine, National Taiwan University Hospital, Taipei, Taiwan \\ ${ }^{3}$ Division of Environmental Health and Occupational Medicine of the National Health Research Institutes, Zhunan, Taiwan \\ Correspondence to: Chin-Hsiao Tseng, email: ccktsh@ms6.hinet.net \\ Keywords: diabetes mellitus, lung cancer, metformin, Taiwan \\ Received: November 10, $2016 \quad$ Accepted: March 22, $2017 \quad$ Published: April 12, 2017 \\ Copyright: Tseng. This is an open-access article distributed under the terms of the Creative Commons Attribution License (CC-BY), which \\ permits unrestricted use, distribution, and reproduction in any medium, provided the original author and source are credited.
}

\section{ABSTRACT}

This study evaluated whether metformin might reduce lung cancer risk. The reimbursement database of the Taiwan's National Health Insurance was used. A sample of 15414 never users and 280159 ever users of metformin (original sample) and a 1:1 matched-pairs of ever and never users ( $n=15414$ in each group, matched sample) were recruited from patients with newly diagnosed type 2 diabetes mellitus during 1999-2005. They were followed until December 31, 2011. Cox regression incorporated with the inverse probability of treatment weighting using propensity score was used to estimate hazard ratios. Results showed that the respective incidence of lung cancer in ever and never users was 173.36 and 292.65 per 100000 person-years in the original sample; and was 211.71 and 292.65 , respectively, in the matched sample. The overall hazard ratios ( $95 \%$ confidence intervals) of $0.586(0.509-0.674)$ in the original sample and 0.717 (0.584-0.881) in the matched sample suggested a significantly lower risk among metformin users. Hazard ratios comparing the first ( $<22.60$ months), second (22.60-46.67 months) and third (>46.67 months) tertile of cumulative duration of metformin use to never users was $1.163(1.005-1.348), 0.612(0.526-0.711)$ and 0.176 $(0.148-0.210)$, respectively, in the original sample; and was $1.465(1.131-1.897), 0.758$ $(0.566-1.016)$ and $0.228(1.460-0.357)$ in the respective tertile of the matched sample. Sensitivity analyses after excluding patients with certain risk factors of cancer and subgroup analyses supported a favorable effect of metformin. In conclusion,metformin use may reduce lung cancer risk in patients with type 2 diabetes mellitus.

\section{INTRODUCTION}

Diabetes mellitus significantly increases the risk of cancer and noncancer deaths [1-4]. According to global statistics, there were 1.8 million new cases of lung cancer in the world in 2012 , accounting for about $13 \%$ of all cancer diagnoses [5]. In Taiwan, lung cancer represents approximately $15 \%$ and $8 \%$ of all cancers in men and women, respectively [6]. Although the incidence of lung cancer is decreasing in men and increasing in women in the whole world [5], it is increasing steadily in both sexes in Taiwan [6,7]. Smoking is the most important risk factor, but air pollution, fumes from cooking and other occupational and environmental exposure to carcinogens such as asbestos, arsenic, radon and polycyclic aromatic hydrocarbons are also potential risk factors [5].

Patients with type 2 diabetes mellitus (T2DM) suffer from a higher risk of various types of cancer including lung cancer $[7,8]$. Epidemiological studies show that metformin may reduce the risk of several types of cancer, including thyroid cancer [9], oral cancer [10], esophageal cancer [11], gastric cancer [12], colon cancer [13], kidney cancer [14], bladder cancer [15], prostate cancer [16], breast cancer [17], endometrial cancer [18], ovarian cancer [19] and cervical cancer [20]. However, whether metformin may reduce the risk of lung cancer remains to be answered. 
There are some observational studies but the conclusions are inconsistent. Tsai et al. reported a reduced risk of lung cancer associated with metformin use [21], but Sakoda et al. did not find such a beneficial effect [22]. Meta-analyses also showed controversial results. In 2013, Wang et al. estimated a pooled relative risk of $0.91(95 \%$ confidence interval: 0.80 -1.03) from 7 observational studies [23]. In 2014, three meta-analyses concluded differently. Zhang et al. pooled the data from 4 studies and showed a significantly lower risk associated with metformin use (pooled relative risk: $0.71,95 \%$ confidence interval: 0.55 $0.95, P=0.02$ ) [24]. However, by including 15 (11 cohort and 4 case-control) observational studies, Nie et al. reported a null association with an adjusted odds ratio of $0.99(95 \%$ confidence interval: 0.87-1.12) [25]. The meta-analysis by Wu et al. (including 15 studies: 11 cohort, 2 case-control and 2 randomized controlled trials) suggested a 15\% risk reduction (odds ratio $0.85,95 \%$ confidence interval: 0.77 0.92 ), but this could not be demonstrated in smokingadjusted subgroup [26]. In 2015, the latest meta-analysis including 8 observational studies by Zhu et al. suggested a significant $16 \%$ risk reduction (relative risk $0.84,95 \%$ confidence interval: 0.73-0.97) [27].

By using the reimbursement databases of the Taiwan's National Health Insurance (NHI), the present study aimed at clarifying whether metformin use in patients with
T2DM might reduce the risk of lung cancer. The tertiles of cumulative duration of metformin therapy were used to evaluate a dose-response relationship. To reduce "prevalent user bias" [28], only patients with newly diagnosed diabetes and new users of metformin were recruited. To reduce "immortal time bias" during the initial period of followup when the outcome can not occur [28], recruited patients should have been prescribed antidiabetic drugs for at least two times, and those who were followed up for $<1$ year were excluded. To reduce the residual confounding from the differences in baseline characteristics, Cox regression models incorporated with the inverse probability of treatment weighting (IPTW) using propensity score (PS) were created to estimate the hazard ratios [29] and additional analyses were conducted in a sample of 1:1 matched-pairs.

\section{RESULTS}

There were 15414 never users and 280159 ever users of metformin in the original sample (Figure 1, Table 1 ). All characteristics differed significantly, except for hypertension, pioglitazone, Epstein-Barr virus (EBV)related diagnoses and hepatitis $\mathrm{B}$ virus (HBV) infection (Table 1). There were 15414 never users and 15414 ever users in the matched-pairs (Figure 1, Table 1 ). Except for age, insulin, sulfonylurea, meglitinide and alcohol-related

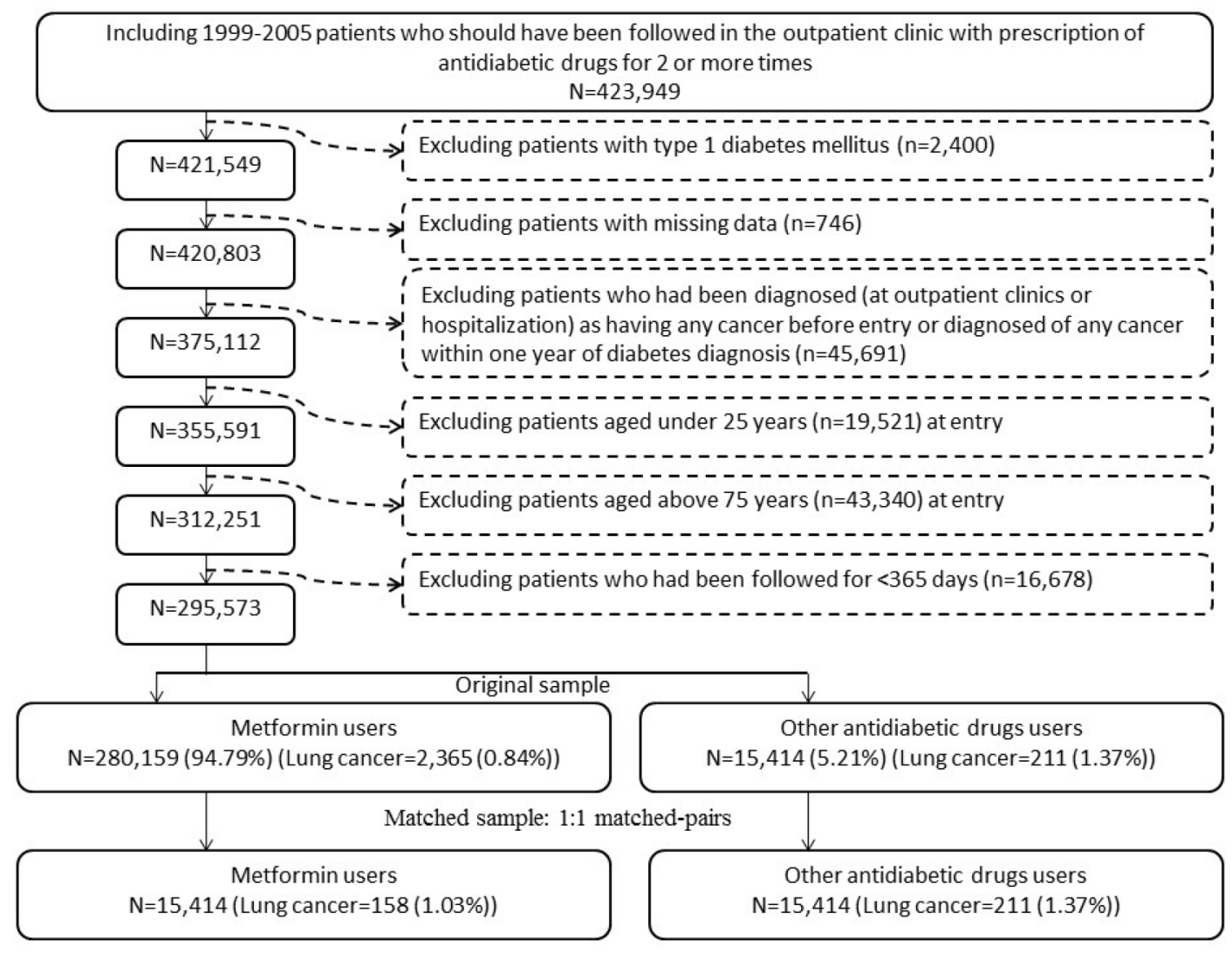

Figure 1: Flowchart showing the procedure in selecting the original sample and the matched sample into the study. 
Table 1: Characteristics of metformin never users and ever users

\begin{tabular}{|c|c|c|c|c|c|c|c|c|c|c|c|c|}
\hline \multirow[t]{3}{*}{ Variable } & \multicolumn{6}{|c|}{ Original sample $(\mathrm{N}=295573)$} & \multicolumn{6}{|c|}{ Matched sample $(\mathrm{N}=30828)$} \\
\hline & \multicolumn{2}{|c|}{$\begin{array}{c}\text { Never users } \\
(n=15414)\end{array}$} & \multicolumn{2}{|c|}{$\begin{array}{l}\text { Ever users } \\
(\mathrm{n}=\mathbf{2 8 0 1 5 9})\end{array}$} & \multirow[t]{2}{*}{$P$ value } & \multirow[t]{2}{*}{ SD } & \multicolumn{2}{|c|}{$\begin{array}{c}\text { Never } \\
\text { users }(n=15414)\end{array}$} & \multicolumn{2}{|c|}{$\begin{array}{c}\text { Ever } \\
\text { users }(n=15414)\end{array}$} & \multirow[t]{2}{*}{$P$ value } & \multirow[t]{2}{*}{ SD } \\
\hline & $\mathbf{n}$ & $\%$ & $\mathbf{n}$ & $\%$ & & & $\mathbf{n}$ & $\%$ & $\mathbf{n}$ & $\%$ & & \\
\hline \multicolumn{13}{|c|}{ Demographic data } \\
\hline Age (years)* & 63.76 & 10.41 & 61.43 & 10.21 & $<0.0001$ & -23.07 & 63.76 & 10.41 & 64.11 & 9.87 & 0.0020 & 4.23 \\
\hline Sex (men) & 8819 & 57.21 & 150517 & 53.73 & $<0.0001$ & -7.27 & 8819 & 57.21 & 8767 & 56.88 & 0.5496 & -0.92 \\
\hline \multicolumn{13}{|l|}{ Occupation } \\
\hline I & 6033 & 39.14 & 113083 & 40.36 & $<0.0001$ & & 6033 & 39.14 & 5952 & 38.61 & 0.5105 & \\
\hline II & 3075 & 19.95 & 64289 & 22.95 & & 7.66 & 3075 & 19.95 & 3074 & 19.94 & & -0.05 \\
\hline III & 3236 & 20.99 & 54670 & 19.51 & & -3.68 & 3236 & 20.99 & 3341 & 21.68 & & 1.85 \\
\hline IV & 3070 & 19.92 & 48117 & 17.17 & & -7.48 & 3070 & 19.92 & 3047 & 19.77 & & -0.49 \\
\hline \multicolumn{13}{|l|}{ Living region } \\
\hline Taipei & 5210 & 33.80 & 94703 & 33.80 & $<0.0001$ & & 5210 & 33.80 & 5198 & 33.72 & 0.6683 & \\
\hline Northern & 1565 & 10.15 & 33569 & 11.98 & & 6.01 & 1565 & 10.15 & 1570 & 10.19 & & -0.03 \\
\hline Central & 2681 & 17.39 & 49963 & 17.83 & & 1.23 & 2681 & 17.39 & 2615 & 16.97 & & -1.14 \\
\hline Southern & 2692 & 17.46 & 44872 & 16.02 & & -4.01 & 2692 & 17.46 & 2782 & 18.05 & & 1.68 \\
\hline $\begin{array}{r}\text { Kao-Ping } \\
\text { and Eastern }\end{array}$ & 3266 & 21.19 & 57052 & 20.36 & & -2.01 & 3266 & 21.19 & 3249 & 21.08 & & 0.00 \\
\hline \multicolumn{13}{|c|}{ Major comorbidities } \\
\hline Hypertension & 12627 & 81.92 & 228657 & 81.62 & 0.3456 & -0.81 & 12627 & 81.92 & 12650 & 82.07 & 0.7332 & 0.60 \\
\hline Dyslipidemia & 11209 & 72.72 & 233135 & 83.22 & $<0.0001$ & 26.93 & 11209 & 72.72 & 11139 & 72.27 & 0.3720 & -0.61 \\
\hline Obesity & 413 & 2.68 & 16082 & 5.74 & $<0.0001$ & 15.36 & 413 & 2.68 & 376 & 2.44 & 0.1821 & -1.36 \\
\hline \multicolumn{13}{|c|}{ Diabetes-related complications } \\
\hline Nephropathy & 5330 & 34.58 & 75028 & 26.78 & $<0.0001$ & -18.17 & 5330 & 34.58 & 5335 & 34.61 & 0.9523 & -0.64 \\
\hline Eye disease & 2911 & 18.89 & 87493 & 31.23 & $<0.0001$ & 29.15 & 2911 & 18.89 & 2786 & 18.07 & 0.0666 & -2.54 \\
\hline Stroke & 5085 & 32.99 & 80963 & 28.90 & $<0.0001$ & -9.35 & 5085 & 32.99 & 5180 & 33.61 & 0.2509 & 1.27 \\
\hline $\begin{array}{l}\text { Ischemic } \\
\text { heart disease }\end{array}$ & 7352 & 47.70 & 127487 & 45.51 & $<0.0001$ & -4.58 & 7352 & 47.70 & 7324 & 47.52 & 0.7495 & -0.23 \\
\hline $\begin{array}{l}\text { Peripheral } \\
\text { arterial } \\
\text { disease }\end{array}$ & 3604 & 23.38 & 70404 & 25.13 & $<0.0001$ & 4.23 & 3604 & 23.38 & 3583 & 23.25 & 0.7773 & -0.43 \\
\hline \multicolumn{13}{|c|}{ Antidiabetic drugs } \\
\hline Insulin & 1243 & 8.06 & 5814 & 2.08 & $<0.0001$ & -29.03 & 1243 & 8.06 & 943 & 6.12 & $<0.0001$ & -9.02 \\
\hline Sulfonylurea & 11298 & 73.30 & 185722 & 66.29 & $<0.0001$ & -12.17 & 11298 & 73.30 & 11844 & 76.84 & $<0.0001$ & 9.58 \\
\hline Meglitinide & 1248 & 8.10 & 10100 & 3.61 & $<0.0001$ & -20.17 & 1248 & 8.10 & 1111 & 7.21 & 0.0033 & -3.14 \\
\hline Acarbose & 1713 & 11.11 & 14193 & 5.07 & $<0.0001$ & -21.80 & 1713 & 11.11 & 1654 & 10.73 & 0.2813 & -2.19 \\
\hline Rosiglitazone & 469 & 3.04 & 12833 & 4.58 & $<0.0001$ & 8.46 & 469 & 3.04 & 441 & 2.86 & 0.3461 & -1.29 \\
\hline Pioglitazone & 391 & 2.54 & 6779 & 2.42 & 0.3582 & -0.09 & 391 & 2.54 & 389 & 2.52 & 0.9422 & -0.39 \\
\hline
\end{tabular}




\begin{tabular}{|c|c|c|c|c|c|c|c|c|c|c|c|c|}
\hline \multirow[t]{3}{*}{ Variable } & \multicolumn{6}{|c|}{ Original sample $(\mathrm{N}=295573)$} & \multicolumn{6}{|c|}{ Matched sample $(\mathrm{N}=\mathbf{3 0 8 2 8})$} \\
\hline & \multicolumn{2}{|c|}{$\begin{array}{l}\text { Never users } \\
(n=15414)\end{array}$} & \multicolumn{2}{|c|}{$\begin{array}{l}\text { Ever users } \\
(n=280159)\end{array}$} & \multirow[t]{2}{*}{$P$ value } & \multirow[t]{2}{*}{ SD } & \multicolumn{2}{|c|}{$\begin{array}{c}\text { Never } \\
\text { users }(n=15414)\end{array}$} & \multicolumn{2}{|c|}{$\begin{array}{c}\text { Ever } \\
\text { users }(n=15414)\end{array}$} & \multirow[t]{2}{*}{$P$ value } & \multirow[t]{2}{*}{ SD } \\
\hline & $\mathbf{n}$ & $\%$ & n & $\%$ & & & n & $\%$ & n & $\%$ & & \\
\hline \multicolumn{13}{|c|}{ Potential risk factors of cancer } \\
\hline COPD & 7659 & 49.69 & 136662 & 48.78 & 0.0280 & -2.17 & 7659 & 49.69 & 7640 & 49.57 & 0.8287 & -0.18 \\
\hline $\begin{array}{l}\text { Tobacco } \\
\text { abuse }\end{array}$ & 431 & 2.80 & 11028 & 3.94 & $<0.0001$ & 6.47 & 431 & 2.80 & 403 & 2.61 & 0.3256 & -1.13 \\
\hline $\begin{array}{l}\text { Alcohol- } \\
\text { related } \\
\text { diagnoses }\end{array}$ & 1178 & 7.64 & 19452 & 6.94 & 0.0009 & -3.36 & 1178 & 7.64 & 1083 & 7.03 & 0.0379 & -2.79 \\
\hline $\begin{array}{l}\text { History of HP } \\
\text { infection }\end{array}$ & 5141 & 33.35 & 84180 & 30.05 & $<0.0001$ & -7.84 & 5141 & 33.35 & 5102 & 33.10 & 0.6372 & -0.92 \\
\hline $\begin{array}{l}\text { EBV-related } \\
\text { diagnoses }\end{array}$ & 109 & 0.71 & 1997 & 0.71 & 0.9352 & 0.06 & 109 & 0.71 & 105 & 0.68 & 0.7838 & -0.31 \\
\hline $\begin{array}{l}\text { HBV } \\
\text { infection }\end{array}$ & 681 & 4.42 & 11704 & 4.18 & 0.1469 & -1.53 & 681 & 4.42 & 631 & 4.09 & 0.1583 & -1.84 \\
\hline $\begin{array}{l}\mathrm{HCV} \\
\text { infection }\end{array}$ & 998 & 6.47 & 14304 & 5.11 & $<0.0001$ & -6.39 & 998 & 6.47 & 951 & 6.17 & 0.2714 & -1.35 \\
\hline \multicolumn{13}{|c|}{ Medications that are commonly used in diabetes patients and may affect cancer risk } \\
\hline ACEI/ARB & 10731 & 69.62 & 204108 & 72.85 & $<0.0001$ & 7.37 & 10731 & 69.62 & 10657 & 69.14 & 0.3605 & -0.95 \\
\hline $\begin{array}{l}\text { Calcium } \\
\text { channel } \\
\text { blocker }\end{array}$ & 9705 & 62.96 & 166164 & 59.31 & $<0.0001$ & -7.70 & 9705 & 62.96 & 9770 & 63.38 & 0.4428 & 0.96 \\
\hline Statin & 8373 & 54.32 & 184811 & 65.97 & $<0.0001$ & 24.99 & 8373 & 54.32 & 8299 & 53.84 & 0.3977 & -0.88 \\
\hline Fibrate & 5303 & 34.40 & 120199 & 42.90 & $<0.0001$ & 18.18 & 5303 & 34.40 & 5259 & 34.12 & 0.5975 & -0.36 \\
\hline Aspirin & 8849 & 57.41 & 171328 & 61.15 & $<0.0001$ & 7.81 & 8849 & 57.41 & 8839 & 57.34 & 0.9083 & 0.04 \\
\hline
\end{tabular}

*Age is expressed as mean and standard deviation

Refer to Materials and Methods for the classification of occupation

SD: standardized difference, COPD: chronic obstructive pulmonary disease, HP: Helicobacter pylori, EBV: Epstein-Barr virus, HBV: hepatitis B virus, $\mathrm{HCV}$ : hepatitis $\mathrm{C}$ virus, $\mathrm{ACEI} / \mathrm{ARB}$ : angiotensin converting enzyme inhibitor/angiotensin receptor blocker

diagnoses, all other variables did not differ significantly between metformin ever and never users (Table 1). While examining the standardized differences, 11 of the variables had values $>10 \%$ in the original sample, but none had a value $>10 \%$ in the matched sample. Therefore, residual confounding from the variables was less likely in the matched sample.

Table 2 shows the incidences of lung cancer by metformin exposure and the hazard ratios comparing exposed to unexposed patients in the original sample and the matched sample, respectively. The respective incidence of lung cancer for ever users and never users was 173.36 and 292.65 per 100,000 person-years in the original sample; and was 211.71 and 292.65 per 100,000 personyears in the matched sample. The overall hazard ratio
(95\% confidence interval) of $0.586(0.509-0.674)$ in the original sample and $0.717(0.584-0.881)$ in the matched sample suggested a significantly lower risk of lung cancer associated with metformin use. When examining lung cancer by the tertiles of cumulative duration, there was a trend of decreasing incidence with longer duration of exposure. A significantly lower risk was observed for the third tertiles, but the first tertiles were associated with a significantly higher risk, in both the original sample and the matched sample.

Table 3 shows the overall hazard ratios in the original sample as sensitivity analyses after excluding patients with certain risk factors of cancer. In all analyses, a significantly lower risk of lung cancer associated with metformin use was observed. 
Table 2: Incidences of lung cancer and hazard ratios by metformin exposure

\begin{tabular}{|c|c|c|c|c|c|c|c|}
\hline Metformin use & $n$ & $N$ & Person-years & $\begin{array}{l}\text { Incidence } \\
\text { rate (per } \\
100,000 \\
\text { person- } \\
\text { years) }\end{array}$ & HR & $95 \% \mathrm{CI}$ & $P$ value \\
\hline \multicolumn{8}{|c|}{ Original sample } \\
\hline Never users & 211 & 15414 & 72099.19 & 292.65 & 1.000 & & \\
\hline Ever users & 2365 & 280159 & 1364192.16 & 173.36 & 0.586 & $(0.509-0.674)$ & $<0.0001$ \\
\hline \multicolumn{8}{|c|}{ Tertiles of cumulative duration of metformin therapy (months) } \\
\hline Never users & 211 & 15414 & 72099.19 & 292.65 & 1.000 & & \\
\hline$<22.60$ & 1190 & 92347 & 358747.29 & 331.71 & 1.163 & $(1.005-1.348)$ & 0.0433 \\
\hline $22.60-46.67$ & 854 & 92759 & 464388.82 & 183.90 & 0.612 & $(0.526-0.711)$ & $<0.0001$ \\
\hline$\geq 46.67$ & 321 & 95053 & 541056.05 & 59.33 & 0.176 & $(0.148-0.210)$ & $<0.0001$ \\
\hline \multicolumn{8}{|c|}{ Matched sample } \\
\hline Never users & 211 & 15414 & 72099.19 & 292.65 & 1.000 & & \\
\hline Ever users & 158 & 15414 & 74631.29 & 211.71 & 0.717 & $(0.584-0.881)$ & 0.0016 \\
\hline \multicolumn{8}{|c|}{ Tertiles of cumulative duration of metformin therapy (months) } \\
\hline Never users & 211 & 15414 & 72099.19 & 292.65 & 1.000 & & \\
\hline$<22.60$ & 80 & 5085 & 19517.80 & 409.88 & 1.465 & $(1.131-1.897)$ & 0.0038 \\
\hline $22.60-47.13$ & 57 & 5088 & 25246.49 & 225.77 & 0.758 & $(0.566-1.016)$ & 0.0641 \\
\hline$\geq 47.13$ & 21 & 5241 & 29867.01 & 70.31 & 0.228 & $(1.460-0.357)$ & $<0.0001$ \\
\hline
\end{tabular}

$n$ : case number of incident lung cancer, $N$ : case number followed

HR: hazard ratio, CI: confidence interval

Table 4 shows the hazard ratios in different subgroups of age, sex, follow-up duration, the presence or absence of diagnoses of chronic obstructive pulmonary disease (COPD)/tobacco abuse, and the use of insulin, sulfonylurea, meglitinide, acarbose, rosiglitazone, pioglitazone, angiotensin converting enzyme inhibitor/angiotensin receptor blocker (ACEI/ARB), calcium channel blocker, statin, fibrate and aspirin. All hazard ratios favored a lower risk of lung cancer associated with metformin use, even though the $P$-values were not significant for the subgroups who had been followed up for $\geq 5$ years or had been using insulin, acarbose or rosiglitazone.

\section{DISCUSSION}

The findings supported a significantly lower risk of lung cancer in patients with T2DM who used metformin (Tables 2-4).

The mechanisms for a reduced risk of lung cancer associated with metformin use remain to be explored. In general, metformin may exert its anticancer effect through the inhibition of tumor angiogenesis [30], suppressing cancer cell metabolism [31], activation of apoptosis and autophagy [32], inhibition of mammalian target of rapamycin (mTOR) [33], immunomodulation by increasing the number of $\mathrm{CD}^{+}$tumor-infiltrating lymphocytes [34], and impairing one-carbon metabolism acting like an antifolate drug [35].

Some in vitro and in vivo studies conducted in lung cancer cells specifically supported these potential mechanisms. The mTOR pathway is upregulated in non-small-cell lung cancer (NSCLC) and metformin inhibits its signaling by directly activating $5^{\prime}$ adenosine monophosphate-activated protein kinase (AMPK) via liver kinase B1 (LKB1) [36]. Metformin may also inhibit the growth of human NSCLC cells by activating AMPK via an LKB1-independent pathway [37]. In in vitro studies, metformin blocks the M2-like polarization of macrophages (important for cancer progression and metastasis) and inhibits metastasis of Lewis lung cancer [38]. Metformin can also act in combination with salinomycin (a putative stem cell killer) to eradicate the NSCLC monolayer cells [39] and sensitize lung cancer cells to chemotherapeutic agents [40]. A meta-analysis suggested that metformin therapy is associated with an improved outcome in lung cancer patients with diabetes [41]. 
Table 3: Sensitivity analyses estimating hazard ratios for lung cancer for ever versus never users of metformin after excluding patients with certain risk factors of cancer

\begin{tabular}{|c|c|c|c|c|c|}
\hline Model & $\begin{array}{c}n / N \text { in ever } \\
\text { users }\end{array}$ & $\begin{array}{l}n / N \text { in never } \\
\text { users }\end{array}$ & HR & $95 \% \mathrm{CI}$ & $P$ value \\
\hline $\begin{array}{l}\text { Excluding patients who developed } \\
\text { other cancers during follow-up }\end{array}$ & $2365 / 262556$ & $211 / 14150$ & 0.578 & $(0.502-0.665)$ & $<0.0001$ \\
\hline $\begin{array}{l}\text { Excluding patients with COPD/ } \\
\text { tobacco abuse }\end{array}$ & $751 / 138825$ & $61 / 7583$ & 0.649 & $(0.500-0.842)$ & 0.0012 \\
\hline $\begin{array}{l}\text { Excluding patients with alcohol- } \\
\text { related diagnoses }\end{array}$ & $2165 / 260707$ & $198 / 14236$ & 0.570 & $(0.493-0.660)$ & $<0.0001$ \\
\hline $\begin{array}{l}\text { Excluding patients with HP } \\
\text { infection }\end{array}$ & 1546 / 195979 & $135 / 10273$ & 0.578 & $(0.484-0.689)$ & $<0.0001$ \\
\hline $\begin{array}{l}\text { Excluding patients with EBV- } \\
\text { related diagnoses }\end{array}$ & 2346 / 278162 & $207 / 15305$ & 0.593 & $(0.514-0.683)$ & $<0.0001$ \\
\hline $\begin{array}{l}\text { Excluding patients with } \mathrm{HBV} / \mathrm{HCV} \\
\text { infection }\end{array}$ & $2152 / 255930$ & 198 / 13864 & 0.561 & $(0.485-0.649)$ & $<0.0001$ \\
\hline
\end{tabular}

$n$ : case number of incident lung cancer, $N$ : case number followed

HR: hazard ratio, CI: confidence interval

COPD: chronic obstructive pulmonary disease, HP: Helicobacter pylori, EBV: Epstein-Barr virus, HBV: hepatitis B virus,

$\mathrm{HCV}$ : hepatitis $\mathrm{C}$ virus

Table 4: Subgroup analyses estimating hazard ratios for lung cancer for ever versus never users of metformin

\begin{tabular}{|c|c|c|c|c|c|}
\hline Model & $n / N$ in ever users & $\begin{array}{c}n / N \text { in never } \\
\text { users }\end{array}$ & HR & $95 \%$ CI & $P$ value \\
\hline Age $<65$ years & $1001 / 174601$ & $105 / 7958$ & 0.503 & $(0.403-0.628)$ & $<0.0001$ \\
\hline Age $\geq 65$ years & 1364 / 105558 & $126 / 7456$ & 0.734 & $(0.611-0.880)$ & 0.0009 \\
\hline Men & $1541 / 150517$ & $133 / 8819$ & 0.649 & $(0.544-0.775)$ & $<0.0001$ \\
\hline Women & 824 / 129642 & $78 / 6595$ & 0.507 & $(0.402-0.639)$ & $<0.0001$ \\
\hline $\begin{array}{l}\text { Follow-up duration }<5 \\
\text { years }\end{array}$ & 2014 / 102702 & 184 / 6200 & 0.557 & $(0.479-0.647)$ & $<0.0001$ \\
\hline $\begin{array}{l}\text { Follow-up duration } \geq 5 \\
\text { years }\end{array}$ & $351 / 177457$ & $27 / 9214$ & 0.694 & $(0.469-1.027)$ & 0.0676 \\
\hline $\begin{array}{l}\text { COPD and/or tobacco } \\
\text { abuse: }(+)\end{array}$ & 1614 / 141334 & $150 / 7831$ & 0.557 & $(0.472-0.659)$ & $<0.0001$ \\
\hline $\begin{array}{l}\text { COPD and/or tobacco } \\
\text { abuse: (-) }\end{array}$ & $751 / 138825$ & $61 / 7583$ & 0.649 & $(0.500-0.842)$ & 0.0012 \\
\hline Insulin use $(+)$ & $42 / 5814$ & $13 / 1243$ & 0.629 & $(0.337-1.171)$ & 0.1437 \\
\hline Insulin use (-) & $2323 / 274345$ & $198 / 14171$ & 0.581 & $(0.502-0.672)$ & $<0.0001$ \\
\hline Sulfonylurea use (+) & $1641 / 185722$ & $162 / 11298$ & 0.581 & $(0.494-0.682)$ & $<0.0001$ \\
\hline Sulfonylurea use (-) & 724 / 94437 & $49 / 4116$ & 0.606 & $(0.454-0.810)$ & 0.0007 \\
\hline Meglitinide use $(+)$ & $96 / 10100$ & $19 / 1248$ & 0.538 & $(0.329-0.879)$ & 0.0135 \\
\hline Meglitinide use (-) & $2269 / 270059$ & $192 / 14166$ & 0.593 & $(0.512-0.687)$ & $<0.0001$ \\
\hline Acarbose use $(+)$ & $147 / 14193$ & $18 / 1713$ & 0.857 & $(0.525-1.398)$ & 0.5368 \\
\hline
\end{tabular}




\begin{tabular}{lccccc}
\hline Model & $\boldsymbol{n} / \boldsymbol{N}$ in ever users & $\begin{array}{c}n / \boldsymbol{N} \text { in never } \\
\text { users }\end{array}$ & HR & $\mathbf{9 5 \%}$ CI & $\boldsymbol{P}$ value \\
\hline Acarbose use (-) & $2218 / 265966$ & $193 / 13701$ & 0.566 & $(0.489-0.656)$ & $<0.0001$ \\
Rosiglitazone use (+) & $117 / 12833$ & $7 / 469$ & 0.587 & $(0.274-1.258)$ & 0.1709 \\
Rosiglitazone use (-) & $2248 / 267326$ & $204 / 14945$ & 0.586 & $(0.508-0.677)$ & $<0.0001$ \\
Pioglitazone use (+) & $41 / 6779$ & $7 / 391$ & 0.283 & $(0.127-0.630)$ & 0.0020 \\
Pioglitazone use (-) & $2324 / 273380$ & $204 / 15023$ & 0.597 & $(0.517-0.688)$ & $<0.0001$ \\
ACEI/ARB use (+) & $1784 / 204108$ & $155 / 10731$ & 0.568 & $0.482-0.669)$ & $<0.0001$ \\
ACEI/ARB use (-) & $581 / 76051$ & $56 / 4683$ & 0.626 & $(0.476-0.824)$ & 0.0008 \\
Calcium channel blocker & $1557 / 166164$ & $144 / 9705$ & 0.592 & $(0.499-0.702$ & $<0.0001$ \\
use (+) & & & & & $<0.0001$ \\
Calcium channel blocker & $808 / 113995$ & $67 / 5709$ & 0.585 & $(0.456-0.751)$ & \\
use (-) & & & & & 0.0018 \\
Statin use (+) & $1392 / 184811$ & $85 / 8373$ & 0.706 & $(0.567-0.879)$ & $<0.0001$ \\
Statin use (-) & $973 / 95348$ & $126 / 7041$ & 0.549 & $(0.456-0.661)$ & $<0.0001$ \\
Fibrate use (+) & $949 / 120199$ & $67 / 5303$ & 0.579 & $(0.452-0.742)$ & $<0.0001$ \\
Fibrate use (-) & $1416 / 159960$ & $144 / 10111$ & 0.601 & $(0.506-0.714)$ & $<0.0001$ \\
Aspirin use (+) & $1530 / 171328$ & $119 / 8849$ & 0.619 & $(0.514-0.746)$ & $<0.0001$ \\
Aspirin use (-) & $835 / 108831$ & $92 / 6565$ & 0.534 & $(0.430-0.662)$ & \\
\hline
\end{tabular}

$n$ : case number of incident lung cancer, $N$ : case number followed

HR: hazard ratio, CI: confidence interval

COPD: chronic obstructive pulmonary disease, ACEI/ARB: angiotensin converting enzyme inhibitor/angiotensin receptor blocker

There is a higher risk of lung cancer in patients with obesity [42]. It is interesting to observe an increased risk in the first tertiles of cumulative duration of metformin therapy (Table 2). A residual confounding from obesity possibly explained such a result because metformin is considered as the first-line treatment for patients with T2DM, especially in those with obesity. Patients categorized in the first tertiles were short-term users and would be characterized by obesity when metformin was preferentially used. The increased risk associated with obesity in patients who were previously on diet control or treated with other medications might be carried over to these short-term users.

The present study has several strengths. First, all claims records of outpatient visits and hospital admission were included and the diagnoses were considered from both sources. Second, most medical co-payments can be waived by the NHI in patients with cancer, and there is a low drug cost-sharing in patients with certain conditions, such as those with a low-income household, veterans or patients with prescription refills for chronic disease. Therefore, the detection rate of lung cancer would be less biased by different social classes. Third, self-reporting bias was much reduced by the use of medical records.
The study limitations included a lack of actual measurement data for confounders such as anthropometric factors, smoking, alcohol drinking, family history, lifestyle, nutritional status, dietary pattern, and genetic parameters. In addition, we did not have exposure data of some occupational and environmental carcinogens and could not evaluate the impact of biochemical data. Another limitation is the lack of information on the pathology, grading and staging of lung cancer. Because adenocarcinoma represents $42 \%$ and $71 \%$ of all cases of lung cancer in men and women, respectively, in Taiwan [43], the findings should better be applied to adenocarcinoma rather than to squamous cell carcinoma, especially in females.

In summary, this study supports that metformin use in Taiwanese patients with T2DM may significantly reduce the risk of lung cancer, especially when it has been used for more than 4 years.

\section{MATERIALS AND METHODS}

The NHI implemented in Taiwan since March 1995 is a compulsory and universal system of health insurance. It covers $>99 \%$ of Taiwan residents and has 
contracts with $>98 \%$ of the hospitals nationwide. The reimbursement databases are handled by the National Health Research Institutes and can be used for academic researches after proposal review and approval by an ethic review board. This study was granted with an approval number 99274.

Individuals were de-identified for the protection of privacy. Diabetes was coded 250.XX and lung cancer 162, based on the International Classification of Diseases, Ninth Revision, Clinical Modification (ICD-9-CM).

Figure 1 shows the procedures in selecting a cohort of patients with newly diagnosed T2DM (original sample) and a 1:1 matched-pairs of sample (matched sample) into the study. The patients should have been diagnosed as having diabetes at an onset age of 25-74 years during the period from 1999 to 2005 . Patients with diabetes mellitus diagnosed during 1996-1998 were excluded to assure a first diagnosis of diabetes after 1999, and they should have been followed up in the outpatient clinic with prescription of antidiabetic drugs for 2 or more times $(n=423949)$. In Taiwan, patients with type 1 diabetes can be waived of much of the co-payment after a certified diagnosis with issuance of a so-called "Severe Morbidity Card". These patients with type 1 diabetes $(n=2400)$ were excluded because metformin is not indicated for them. Patients with missing data $(n=746)$, with a diagnosis of any cancer before entry or within one year of diabetes diagnosis $(n=45691)$, aged $<25(n=19521)$ or $\geq 75(n=43340)$ years, and followed up for $<365$ days $(n=16678)$ were also excluded. As a result, there were 280159 patients who had ever been treated with metformin and 15414 patients who had never been treated with metformin (the original sample).

Because the characteristics might be imbalanced between metformin ever users and never users in the original sample, additional analyses were conducted in a sample of 1:1 PS matched-pairs (the matched sample). The matched sample was created by using the Greedy $8 \rightarrow 1$ digit match algorithm proposed by Parsons (the matching macro using SAS statistical software is available online) [44]. The PS was derived from all characteristics listed in Table 1 plus the date of entry by using logistic regression. Because the case number of never users was much smaller than ever users in the original sample, the number of matched-pairs of ever and never users was based on the case number of never users in the original sample (i.e., $n=15414$ ). Therefore, one case in the pool of ever users in the original sample was selected as a matched-pair to each of the never users. According to the matching algorithm, the best match with the highest 8 digits of the PS was first selected. If a matched-pair was made, no more matching was considered. If not, ever users would then be matched on 7 digits of the PS to the never users. The procedures were repeated sequentially to the lowest digit of PS until a matched-pair was made [44]. This matching method has been used in our previous studies [10, 12, 20, 45, 46].
Cumulative duration (months) of metformin use was calculated and its tertiles were used. Demographic data of age, sex, occupation and living region, and factors that might be correlated with metformin use, diabetes severity or cancer risk were considered as potential confounders. The living region and occupation were classified as detailed elsewhere [13]. In brief, the living region was classified as Taipei, Northern, Central, Southern, and Kao-Ping/ Eastern. Occupation was classified as class I (civil servants, teachers, employees of governmental or private businesses, professionals and technicians), class II (people without a specific employer, self-employed people or seamen), class III (farmers or fishermen) and class IV (low-income families supported by social welfare, or veterans).

Other confounders included 1) major comorbidities associated with diabetes mellitus: hypertension (ICD-9-CM code: 401-405), dyslipidemia (272.0-272.4) and obesity (278); 2) diabetes-related complications: nephropathy (580$589)$, eye disease $(250.5,362.0,369,366.41$ and 365.44$)$, stroke (430-438), ischemic heart disease (410-414), and peripheral arterial disease $(250.7,785.4,443.81$ and 440448); 3) antidiabetic drugs: insulin, sulfonylurea, meglitinide, acarbose, rosiglitazone and pioglitazone; 4) potential risk factors of cancer: COPD (a surrogate of smoking; 490-496), tobacco abuse (305.1, 649.0 and 989.84), alcohol-related diagnoses (291, 303, 535.3, 571.0-571.3 and 980.0), history of Helicobacter pylori (HP) infection (defined below), diagnoses related to EBV infection $(075,710.3$ and 710.4$)$, HBV infection (070.22, 070.23, 070.32, 070.33 and V02.61) and hepatitis $\mathrm{C}$ virus infection (070.41, 070.44, 070.51, 070.54 and V02.62); and 5) medications that are commonly used in diabetes patients and may potentially affect cancer risk: ACEI/ARB, calcium channel blocker, statin, fibrate and aspirin. History of HP infection was defined based on one of the following two criteria: 1) having received an HP eradication therapy (detailed previously [47] and defined in brief as a combination use of proton pump inhibitors or $\mathrm{H} 2$ receptor blockers, plus clarithromycin, metronidazole or levofloxacin, plus amoxicillin or tetracycline, with or without bismuth, in the same prescription order for 7-14 days); and/or 2) HP infection diagnosis (041.86).

The characteristics between never users and ever users were compared by Student's t test for age and by Chi-square test for other variables. The standardized differences proposed by Austin and Stuart as a test for balance diagnostics were calculated for all covariates [48]. A value of $>10 \%$ might indicate potential confounding from the variable [48].

The incidence density of lung cancer was calculated for never users, ever users and tertiles of cumulative duration of metformin therapy. The numerator was the case number of incident lung cancer during follow-up, and the denominator was the person-years of follow-up. Follow-up started on the first day of the use of antidiabetic drugs and ended on December 31, 2011, at the time of a new diagnosis of lung cancer, or on the date of death or the last reimbursement record. 
The treatment effect was estimated by Cox regression incorporated with IPTW using the PS [29]. Hazard ratios were estimated for ever versus never users and for each tertile of cumulative duration of metformin therapy using never users as referent.

Sensitivity analyses were conducted in the original sample by estimating the overall hazard ratios for ever versus never users after excluding patients with certain risk factors of cancer. These analyses were conducted after excluding 1) patients who developed other cancers during follow-up; 2) patients with COPD/tobacco abuse; 3) patients with alcohol-related diagnoses; and 4) patients with infections of HP, EBV and $\mathrm{HBV} / \mathrm{HCV}$, respectively.

Subgroup analyses were also conducted to examine the consistency of the findings. Hazard ratios were estimated for subgroups of age $<65$ years, age $\geq 65$ years, men, women, follow-up duration $<5$ years, follow-up duration $\geq 5$ years, COPD/tobacco abuse $(+), \mathrm{COPD} /$ tobacco abuse (-) and with and without the use of certain medications (i.e., insulin, sulfonylurea, meglitinide, acarbose, rosiglitazone, pioglitazone, ACEI/ARB, calcium channel blocker, statin, fibrate and aspirin).

Analyses were conducted using SAS statistical software, version 9.3 (SAS Institute, Cary, NC). $P<0.05$ was considered statistically significant.

\section{ACKNOWLEDGMENTS}

The study is based in part on data from the National Health Insurance Research Database provided by the Bureau of National Health Insurance, Department of Health and managed by National Health Research Institutes. The interpretation and conclusions contained herein do not represent those of Bureau of National Health Insurance, Department of Health or National Health Research Institutes.

\section{FUNDING}

The study was supported by the Ministry of Science and Technology (MOST 103-2314-B-002-187-MY3) of Taiwan. The funders had no role in study design, data collection and analysis, decision to publish, or preparation of the manuscript. The publication fee of this paper is supported by the Weng Yuan Endocrine Fund.

\section{CONFLICTS OF INTEREST}

The author declares no conflicts of interest.

\section{REFERENCES}

1. Tseng $\mathrm{CH}$. Mortality and causes of death in a national sample of diabetic patients in Taiwan. Diabetes Care. 2004; 27:1605-09.
2. Tseng CH, Chong CK, Tseng CP, Cheng JC, Wong MK, Tai TY. Mortality, causes of death and associated risk factors in a cohort of diabetic patients after lower-extremity amputation: a 6.5-year follow-up study in Taiwan. Atherosclerosis. 2008; 197:111-17.

3. Tseng CH. Obesity paradox: differential effects on cancer and noncancer mortality in patients with type 2 diabetes mellitus. Atherosclerosis. 2013; 226:186-92.

4. Tseng $\mathrm{CH}$. Factors associated with cancer- and non-cancerrelated deaths among Taiwanese patients with diabetes after 17 years of follow-up. PLoS One. 2016; 11:e0147916.

5. Torre LA, Bray F, Siegel RL, Ferlay J, Lortet-Tieulent J, Jemal A. Global cancer statistics, 2012. CA Cancer J Clin. 2015; 65:87-108.

6. Chiang CJ, Chen YC, Chen CJ, You SL, Lai MS, and Taiwan Cancer Registry Task Force. Cancer trends in Taiwan. Jpn J Clin Oncol. 2010; 40:897-904.

7. Tseng CH. Diabetes but not insulin increases the risk of lung cancer: a Taiwanese population-based study. PLoS One. 2014; 9:e101553.

8. Tseng $\mathrm{CH}$. Higher risk of mortality from lung cancer in Taiwanese people with diabetes. Diabetes Res Clin Pract. 2013; 102:193-201.

9. Tseng $\mathrm{CH}$. Metformin reduces thyroid cancer risk in Taiwanese patients with type 2 diabetes. PLoS One. 2014; 9:e109852.

10. Tseng $\mathrm{CH}$. Metformin may reduce oral cancer risk in patients with type 2 diabetes. Oncotarget. 2016; 7:2000-08. doi: 10.18632/oncotarget.6626.

11. Tseng $\mathrm{CH}$. Metformin and esophageal cancer risk in Taiwanese patients with type 2 diabetes mellitus. Oncotarget. 2017; 8:18802-10. doi: 10.18632/ oncotarget.13390.

12. Tseng $\mathrm{CH}$. Metformin reduces gastric cancer risk in patients with type 2 diabetes mellitus. Aging (Albany NY). 2016; 8:1636-49. doi: 10.18632/aging.101019.

13. Tseng CH. Diabetes, metformin use, and colon cancer: a population-based cohort study in Taiwan. Eur J Endocrinol. 2012; 167:409-16.

14. Tseng $\mathrm{CH}$. Use of metformin and risk of kidney cancer in patients with type 2 diabetes. Eur J Cancer. 2016; 52:19-25.

15. Tseng $\mathrm{CH}$. Metformin may reduce bladder cancer risk in Taiwanese patients with type 2 diabetes. Acta Diabetol. 2014; 51:295-303.

16. Tseng $\mathrm{CH}$. Metformin significantly reduces incident prostate cancer risk in Taiwanese men with type 2 diabetes mellitus. Eur J Cancer. 2014; 50:2831-37.

17. Tseng $\mathrm{CH}$. Metformin may reduce breast cancer risk in Taiwanese women with type 2 diabetes. Breast Cancer Res Treat. 2014; 145:785-90.

18. Tseng $\mathrm{CH}$. Metformin and endometrial cancer risk in Chinese women with type 2 diabetes mellitus in Taiwan. Gynecol Oncol. 2015; 138:147-53. 
19. Tseng $\mathrm{CH}$. Metformin reduces ovarian cancer risk in Taiwanese women with type 2 diabetes mellitus. Diabetes Metab Res Rev. 2015; 31:619-26.

20. Tseng $\mathrm{CH}$. Metformin use and cervical cancer risk in female patients with type 2 diabetes. Oncotarget. 2016; 7:5954855. doi: 10.18632/oncotarget.10934.

21. Tsai MJ, Yang CJ, Kung YT, Sheu CC, Shen YT, Chang PY, Huang MS, Chiu HC. Metformin decreases lung cancer risk in diabetic patients in a dose-dependent manner. Lung Cancer. 2014; 86:137-43.

22. Sakoda LC, Ferrara A, Achacoso NS, Peng T, Ehrlich SF, Quesenberry CP Jr, Habel LA. Metformin use and lung cancer risk in patients with diabetes. Cancer Prev Res (Phila). 2015; 8:174-79.

23. Wang Z, Bao C, Su C, Xu W, Luo H, Chen L, Qi X. Association between diabetes or antidiabetic therapy and lung cancer: A meta-analysis. J Diabetes Investig. 2013; 4:659-66.

24. Zhang ZJ, Bi Y, Li S, Zhang Q, Zhao G, Guo Y, Song Q. Reduced risk of lung cancer with metformin therapy in diabetic patients: a systematic review and meta-analysis. Am J Epidemiol. 2014; 180:11-14.

25. Nie SP, Chen H, Zhuang MQ, Lu M. Anti-diabetic medications do not influence risk of lung cancer in patients with diabetes mellitus: a systematic review and metaanalysis. Asian Pac J Cancer Prev. 2014; 15:6863-69.

26. Wu Y, Liu HB, Shi XF, Song Y. Conventional hypoglycaemic agents and the risk of lung cancer in patients with diabetes: a meta-analysis. PLoS One. 2014; 9:e99577.

27. Zhu N, Zhang Y, Gong YI, He J, Chen X. Metformin and lung cancer risk of patients with type 2 diabetes mellitus: A meta-analysis. Biomed Rep. 2015; 3:235-41.

28. Yang XL, Ma RC, So WY, Kong AP, Xu G, Chan JC. Addressing different biases in analysing drug use on cancer risk in diabetes in non-clinical trial settings - what, why and how? Diabetes Obes Metab. 2012; 14:579-85.

29. Austin PC. The performance of different propensity score methods for estimating marginal hazard ratios. Stat Med. 2013; 32:2837-49.

30. Wang J, Li G, Wang Y, Tang S, Sun X, Feng X, Li Y, Bao G, Li P, Mao X, Wang M, Liu P. Suppression of tumor angiogenesis by metformin treatment via a mechanism linked to targeting of HER2/HIF-1 $\alpha$ /VEGF secretion axis. Oncotarget. 2015; 6:44579-92. doi: 10.18632/oncotarget.6373.

31. Wong VK, Dong H, Liang X, Bai LP, Jiang ZH, Guo Y, Kong AN, Wang R, Kam RK, Law BY, Hsiao WW, Chan KM, Wang J, et al. Rh2E2, a novel metabolic suppressor, specifically inhibits energy-based metabolism of tumor cells. Oncotarget. 2016; 7:9907-24. doi: 10.18632/oncotarget.6373.

32. Nazim UM, Moon JH, Lee JH, Lee YJ, Seol JW, Eo SK, Lee JH, Park SY. Activation of autophagy flux by metformin downregulates cellular FLICE-like inhibitory protein and enhances TRAIL- induced apoptosis. Oncotarget. 2016; 7:23468-81. doi: 10.18632/oncotarget.8048.
33. Chae YK, Arya A, Malecek MK, Shin DS, Carneiro B, Chandra S, Kaplan J, Kalyan A, Altman JK, Platanias L, Giles F. Repurposing metformin for cancer treatment: current clinical studies. Oncotarget. 2016; 7:40767-80. doi: 10.18632/oncotarget.8194.

34. Eikawa S, Nishida M, Mizukami S, Yamazaki C, Nakayama E, Udono H. Immune-mediated antitumor effect by type 2 diabetes drug, metformin. Proc Natl Acad Sci USA. 2015; 112:1809-14.

35. Corominas-Faja B, Quirantes-Piné R, Oliveras-Ferraros C, Vazquez-Martin A, Cufí S, Martin-Castillo B, Micol V, Joven J, Segura-Carretero A, Menendez JA. Metabolomic fingerprint reveals that metformin impairs one-carbon metabolism in a manner similar to the antifolate class of chemotherapy drugs. Aging (Albany NY). 2012; 4:480-98. doi: 10.18632/aging.100472.

36. Han D, Li SJ, Zhu YT, Liu L, Li MX. LKB1/AMPK/mTOR signaling pathway in non-small-cell lung cancer. Asian Pac J Cancer Prev. 2013; 14:4033-39.

37. Guo Q, Liu Z, Jiang L, Liu M, Ma J, Yang C, Han L, Nan $\mathrm{K}$, Liang X. Metformin inhibits growth of human non-small cell lung cancer cells via liver kinase B-1-independent activation of adenosine monophosphate-activated protein kinase. Mol Med Rep. 2016; 13:2590-96.

38. Ding L, Liang G, Yao Z, Zhang J, Liu R, Chen H, Zhou $\mathrm{Y}$, Wu H, Yang B, He Q. Metformin prevents cancer metastasis by inhibiting M2-like polarization of tumor associated macrophages. Oncotarget. 2015; 6:36441-55. doi: 10.18632/oncotarget.5541.

39. Xiao Z, Sperl B, Ullrich A, Knyazev P. Metformin and salinomycin as the best combination for the eradication of NSCLC monolayer cells and their alveospheres (cancer stem cells) irrespective of EGFR, KRAS, EML4/ALK and LKB1 status. Oncotarget. 2014; 5:12877-90. 10.18632/ oncotarget.2657.

40. Li L, Wang Y, Peng T, Zhang K, Lin C, Han R, Lu C, He Y. Metformin restores crizotinib sensitivity in crizotinibresistant human lung cancer cells through inhibition of IGF1-R signaling pathway. Oncotarget. 2016; 7:34442-52. doi: 10.18632/oncotarget.9120.

41. Wan G, Yu X, Chen P, Wang X, Pan D, Wang X, Li L, Cai X, Cao F. Metformin therapy associated with survival benefit in lung cancer patients with diabetes. Oncotarget. 2016; 7:35437-45. doi: 10.18632/oncotarget.8881.

42. Dewi NU, Boshuizen HC, Johansson $M$, Vineis $P$, Kampman E, Steffen A, Tjønneland A, Halkjær J, Overvad K, Severi G, Fagherazzi G, Boutron-Ruault MC, Kaaks R, et al. Anthropometry and the risk of lung cancer in EPIC. Am J Epidemiol. 2016; 184:129-39.

43. Bureau of Health Promotion. Cancer Registry Annual Report 2008. Taiwan: Department of Health, Executive Yuan, 2010. http://www.hpa.gov.tw/DOWNLOAD/Statisti cs $/ 1 . \% \mathrm{E} 7 \% 99 \% 8 \mathrm{C} \% \mathrm{E} 7 \% 97 \% 87 \% \mathrm{E} 7 \% 99 \% \mathrm{BB} \% \mathrm{E} 8 \% \mathrm{~A} 8 \%$ 98\%E5\%B9\%B4\%E5\%BA\%A6\%E5\%A0\%B1\%E5\%91\% $8 \mathrm{~A} \% \mathrm{EF} \% \mathrm{BC} \% 88 \% \mathrm{E} \%$ \%85\% $8 \% \mathrm{EF} \% \mathrm{BC} \% 89(92 \% \mathrm{E} \%$ B 
9\%B4\%E4\%BB $\%$ A5\%Е5\%BE $\% 8 \mathrm{C} \% \mathrm{E} \%$ B3 $\% 87 \% \mathrm{E} 6 \% 9$

$6 \% 99 \% \mathrm{E} 5 \% 83 \% 85 \% \mathrm{E} 5 \% 90 \% \mathrm{AB} \% \mathrm{E} 4 \% \mathrm{BE} \% \mathrm{~B} 5 \% \mathrm{E} \% \mathrm{~A} 5$

\%B2\%E7\%99\%8C)/Y97-\%E7\%99\%8C\%E7\%97\%87\%E7

\%99\%BB\%Е8\%A $\% 98 \%$ E5\%B9\%B4\%Е5\%BA\%A6\%Е5

$\%$ A0\%B1\%E5\%91\%8A\%EF\%BC\%88\%E5\%85\%A8).pdf

(21 October 2014, date last accessed)

44. Parsons LS. Performing a $1: \mathrm{N}$ case-control match on propensity score. http://www.google.com.tw/url?sa=t\&rct=j $\& q=\&$ esrc $=$ s\&source $=$ web $\& c d=1 \& v e d=0 \mathrm{CBsQFjAAahUK}$ Ewibi7HllcnIAhUDoJQKHVeZA9A\&url=http $\% 3 \mathrm{~A} \% 2 \mathrm{~F} \%$ 2Fwww2.sas.com\%2Fproceedings\%2Fsugi29\%2F165-29. pdf\&usg=AFQjCNFOHGWYu8E8Bn4-Bo1TUiJKtT987Q (last accessed October 17, 2015).
45. Tseng CH. Sitagliptin use and thyroid cancer risk in patients with type 2 diabetes. Oncotarget. 2016; 7:24871-79. doi: 10.18632/oncotarget.8399.

46. Tseng $\mathrm{CH}$. Sitagliptin and heart failure hospitalization in patients with type 2 diabetes. Oncotarget. 2016; 7:6268796. doi: 10.18632/oncotarget.10507.

47. Tseng $\mathrm{CH}$. Diabetes, insulin use and Helicobacter pylori eradication: a retrospective cohort study. BMC Gastroenterol. 2012; 12:46.

48. Austin PC, Stuart EA. Moving towards best practice when using inverse probability of treatment weighting (IPTW) using the propensity score to estimate causal treatment effects in observational studies. Stat Med. 2015; 34:3661-79. 